\title{
Short term temperature fluctuations affect embryonic and larval development of yellow perch (Perca flavescens)
}

\begin{abstract}
Early life stages of fishes are critical stages due to their importance in enhancing recruitment. Given the high mortality through the embryonic and larval stages, managers have started investigating factors that impact these stages. Environmental factors, such as water temperature, have been found to play a larger role in early life survival. Climate change predications will be more apparent in northern temperate systems like the Great Lakes. Yellow perch Perca flavescens are an important sport fish in the region whose populations have been declining since the 1980 s. Yellow perch recruitment is highly erratic due to the species dependence on spring water temperatures. With warming waters occurring earlier in the seasons, it is unsure how wild yellow perch will adapt. The objective of this study was to determine how variations in temperature regimes during the egg incubation period would impact embryonic and larval development in yellow perch. Four different temperature treatments were used in this study: steady temperature at $16^{\circ} \mathrm{C}$, a gradient starting at $12^{\circ} \mathrm{C}$ increasing by $1-2^{\circ} \mathrm{C}$ every 3-4 days, a heat shock on day six of $20^{\circ} \mathrm{C}$ for 16 hours to mimic a heat wave event, and finally, a cold shock on day six of $10^{\circ} \mathrm{C}$ temperatures for 16 hours to mimic a cold snap event. The results of this study confirm that water temperatures severely impact embryonic development and incubation periods of yellow perch, having a significant impact on the percent of failed larvae at the end of the incubation period $(P=$ $0.0005)$, with the cold shock affecting the lowest percent of failed larvae $(0.8 \%)$ while the steady treatment had the highest percent $(22.9 \%)$. Temperature treatment did have a significant impact on the time it took for larvae to successfully hatch out $(P<0.001)$, but no significant effect on observed mortality and estimated mortality $(P=0.96)$, percent of surviving larvae $(P=0.35)$, or average growth rate of larvae $(P=0.16)$. This study reveals that yellow perch are better adapted to withstand acute cold shifts in water temperature than acute warming events. Climate change could potentially hinder an already struggling Lake Michigan yellow perch population.
\end{abstract}

Volume 10 Issue 4 - 2021

\author{
Anne M Schmitz,' Osvaldo J Sepulveda Villet ${ }^{2}$ \\ 'Wisconsin Department of Natural Resources Northeast \\ Regional Fisheries Unit, USA \\ 'University of Wisconsin-Milwaukee School of Freshwater \\ Sciences, USA
}

Correspondence: Osvaldo J Sepulveda Villet, University of Wisconsin-Milwaukee School of Freshwater Sciences, $600 \mathrm{E}$ Greenfield Ave. Milwaukee,WI 53204, USA,

Tel+I (4I4)382-I740, Email sepulveo@uwm.edu

Received: August 15, 202I | Published: September 01, 202 I

\section{Introduction}

Life history of fishes have been studied for years in ecological systems. However, gaps in early life adaptations due to natural and anthropogenic stressors have become apparent as management needs have changed. ${ }^{1}$ The stage of life history that defines year class strength for fish does vary depending on the environment and species, however the bottleneck for recruitment often occurs during the first-year post-spawn for many species such as: yellow perch, African sharptooth catfish Clarias gariepinus, and herring Clupea harengusm. ${ }^{2-4}$ It is commonly accepted that a high mortality rate ( $99 \%)$ occurs through these early life developmental stages, specifically during the embryonic and larval stages compared to juvenile stages for yellow perch, ${ }^{2,5}$ European sardine Sardina pilchardus, ${ }^{6}$ lake sturgeon Ascipenser fulvescens ${ }^{7}$ and northern pike Esox lucius. ${ }^{8}$

During the critical processes of embryonic and larval development, young individuals are sensitive to environmental conditions. ${ }^{8,9,10}$ However, it has been found that fish eggs can tolerate temperature changes of $\pm 6^{\circ} \mathrm{C}$ without incurring serious negative impacts. ${ }^{11}$ Rutherford et al. ${ }^{10}$ found that walleye Sander vitreus eggs were sensitive to temperature changes within the first 10 days post-fertilization. Embryos exposed to a heat shock could become immunocompromised and larval size could be negatively impacted. ${ }^{12}$

Water temperatures often dictate hatching and survival of most larval fish. ${ }^{10}$ Major die-offs could be an effect of extreme climatic events (heat waves, hurricanes, severe cold snaps, floods, etc.) which are projected to increase in frequency due to climate change. ${ }^{13}$ Infrequent thermal shocks (heat or cold) during the embryonic and larval phases could cause large larval mortality events. ${ }^{11,12,14}$ If perturbations persist long-term, life history stages could change resulting in shifts in spawning phenology impacting offspring size and reproductive success..$^{15,16}$

Few studies have investigated how temperature impacts hatch phenology (duration of hatching including peak hatch). ${ }^{5,17}$ Generally, the reproductive season remains stable, occurring in the same season each year. However, fish populations may shift timings of spawning within normal reproductive seasons. ${ }^{5}$ Variation in spawning timing could have an impact on subsequent recruitment. ${ }^{5}$ Hatching earlier in the season is often assumed to increase the fitness of offspring for species such as pumpkinseed Lepomis gibbous, ${ }^{18}$ northern pike, ${ }^{19,20}$ and yellow perch. ${ }^{21}$ Increasing fluctuations in water temperatures during incubation and hatching periods could disfavor early hatching offspring if food availability is scarce. ${ }^{14,20}$ Projected climate-driven changes to thermal conditions may produce faster spring warming and longer stratification in lakes. In Lake Erie, both walleye and yellow perch spawn earlier following a warm winter with an early spring onset compared to cold winters with a delayed spring onset. ${ }^{21}$ Prolonged incubation periods due to colder water temperatures in northern pike had low larval survivorship as well as an increase in malformed larvae. ${ }^{19}$ 
In the Great Lakes region, yellow perch are a favored recreational sport fish and important commercial species in areas where they are abundant. ${ }^{2,16,22,23,24}$ Yellow perch are typically found in the shallower, more productive basins around the lakes, such as Green Bay (Lake Michigan) and the western basin of Lake Erie. ${ }^{16}$ Over the last decades, yellow perch recruitment has become exceedingly erratic. ${ }^{25}$ Yellow perch recruitment variability is dependent on spring temperatures on a broad scale but biotic factors at a local scale (e.g. food availability and predator adundance)also are a source of differentiation in recruitment. ${ }^{2,5,23,26}$ Yellow perch and Eurasian perch Perca fluviatilis year-class strength is the highest during springs with stable, warm water temperatures while low year-class strength is connected to springs with water temperature fluctuations. ${ }^{27,28}$ Yellow perch spawning events often occur in very narrow time periods, some have been documented as lasting only five days. ${ }^{2,5}$ For this reason, yellow perch are more susceptible to weak year classes or failures. ${ }^{5,28}$ In the Great Lakes, a few year classes typically dominate the population structure of yellow perch. ${ }^{22}$ Ohlberger and Langangen ${ }^{13}$ found that populations that are only dominated by a few year classes are at a higher risk of a population crash with little chance of recovery. This type of collapse has already been documented in the Lake Michigan yellow perch population. The collapse could be due to both bottom-up and top-down effects on yellow perch in the Great Lakes. ${ }^{29,30,31}$

Climate change may have a negative effect on yellow perch recruitment during embryonic development by altering the incubation and hatching period of larval yellow perch. ${ }^{16,32}$ Water temperature is believed to play a primary role in yellow perch reproduction and early life survival. ${ }^{25,27}$ There have been previous studies that claim potential warming waters may benefit yellow perch in the Great Lakes. However, a study by Farmer et al. ${ }^{21}$ found that warm winters may reduce egg quality and embryonic development leading to a decrease in hatching success of yellow perch. Yellow perch would be expected to shift their spawning period to earlier in spring as a result of the prediction of earlier spring onsets. ${ }^{16}$ Lyons et al. ${ }^{17}$ documented earlier spawning in Lake Michigan yellow perch in response to earlier spring onset with advancements by 1.8 to 6.8 days per decade since the 1980s. The shift that yellow perch demonstrate following a warm winter is somewhat constrained (only advancing by a week) relative to a thermal regime shift (advancement by three weeks)causing a mismatch with prey. ${ }^{16,21}$

The objective of this study was to determine how variations in temperature regimes during the egg incubation period would impact embryonic and larval development in yellow perch.To achieve this, yellow perch were hatched and observed throughout the full larval stage. Several hypotheses were addressed within this objective: 1) Temperature treatments will not impact egg or larval mortality throughout incubation 2) Temperature treatments will not impact production of larvae 3) Temperature treatments will not impact the incubation period (i.e. time of hatch out of larvae) 4) Temperature treatments will not impact initial size, growth, or final size of larvae.

\section{Methods}

Gametes were collected from the laboratory of Fred Binkowski at the University of Wisconsin-Milwaukee School of Freshwater Sciences (Milwaukee, Wisconsin). The strain of yellow perch used in this study was a Northeast River strain broodstock originating from wild yellow perch gametes from the Northeast River in Chesapeake Bay, Maryland. The broodstock used in this study is the F-1 generation and has been managed for six years at the School of Freshwater Sciences.
Milt was collected from three different males and pooled together eliminating any potential male variation over the course of the study. An immobilization solution (.33M sucrose solution) was added to preserve the milt ensuring all eggs were fertilized with the same milt. ${ }^{33,34}$ Once egg ribbons were acquired from five different females, each female was kept for weight and length measurements. Each egg skein was fertilized with $50 \mathrm{~mL}$ of the preserved milt solution. Prior to splitting each egg ribbon up into experimental replicates, total weight and volume of each ribbon was recorded.

The experiment was a randomized block design with the blocking factor as females. This was done to account for variation in females while primarily testing how temperature impacts embryonic and larval development. Egg ribbons were divided into four segments. One segment from each female was put into each of the four temperature treatments (Figure 1). The temperature treatments were as follows:

1. Steady Treatment: eggs were held at $16^{\circ} \mathrm{C}$ for entire incubation period.

2. Standard Treatment: Common gradient increase in temperature throughout incubation starting at $12^{\circ} \mathrm{C}$ increasing by $1-2^{\circ} \mathrm{C}$ every 3-4 days.

3. Heat Shock Treatment: on day six of incubation eggs were exposed to $20^{\circ} \mathrm{C}$ temperatures for 16 hours to mimic a heat wave event.

4. Cold Shock Treatment: on day six of incubation eggs were exposed to $10^{\circ} \mathrm{C}$ temperatures for 16 hours to mimic a cold snap event.
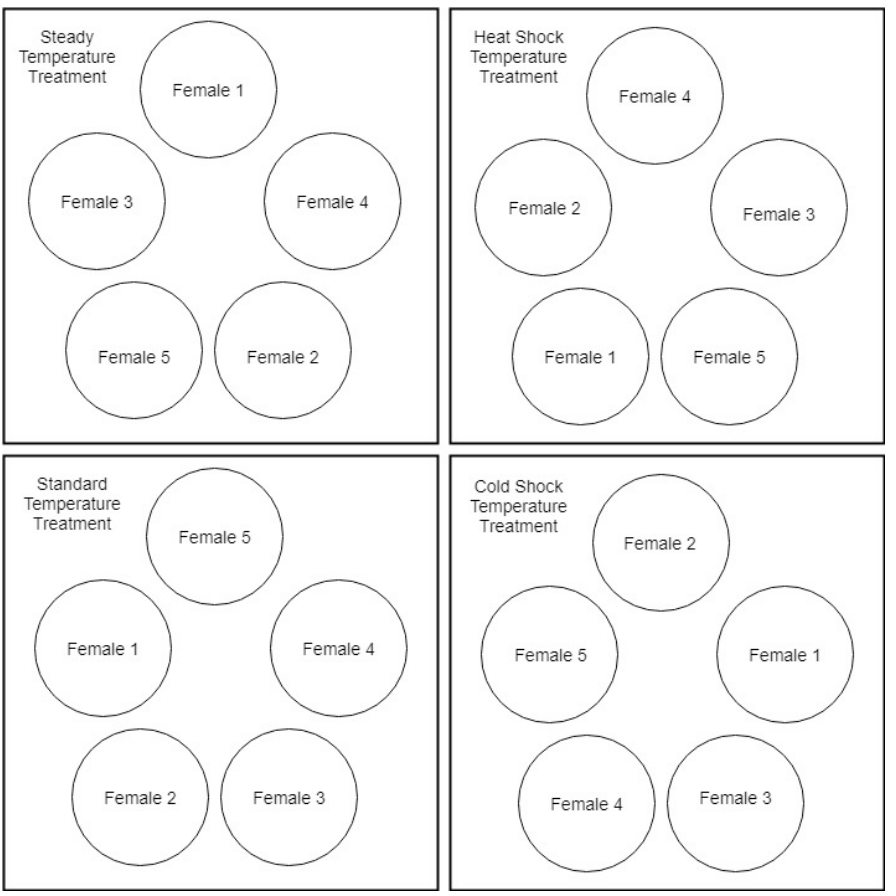

Figure I Embryonic Development Experimental Design. Egg ribbons from each female were randomly assigned to a replicate within each treatment block. Each temperature treatment was separate from the others. Embryonic development was observed during the incubation period until larvae started to hatch-out.

Temperature treatments were set up on individual sump systems to run all the treatments at the same time. Each temperature treatment 
system contained five $3.5 \mathrm{~L}$ plastic buckets housed in 25 -gallon tank inserts (Figure 1). Each female egg segment was kept separate per treatment and was randomly assigned to a bucket. Once larvae started hatching out, a select number from each replicate were moved to $6 \mathrm{~L}$ buckets housed in 25-gallon tank insertson the same sump system (Figure 2).
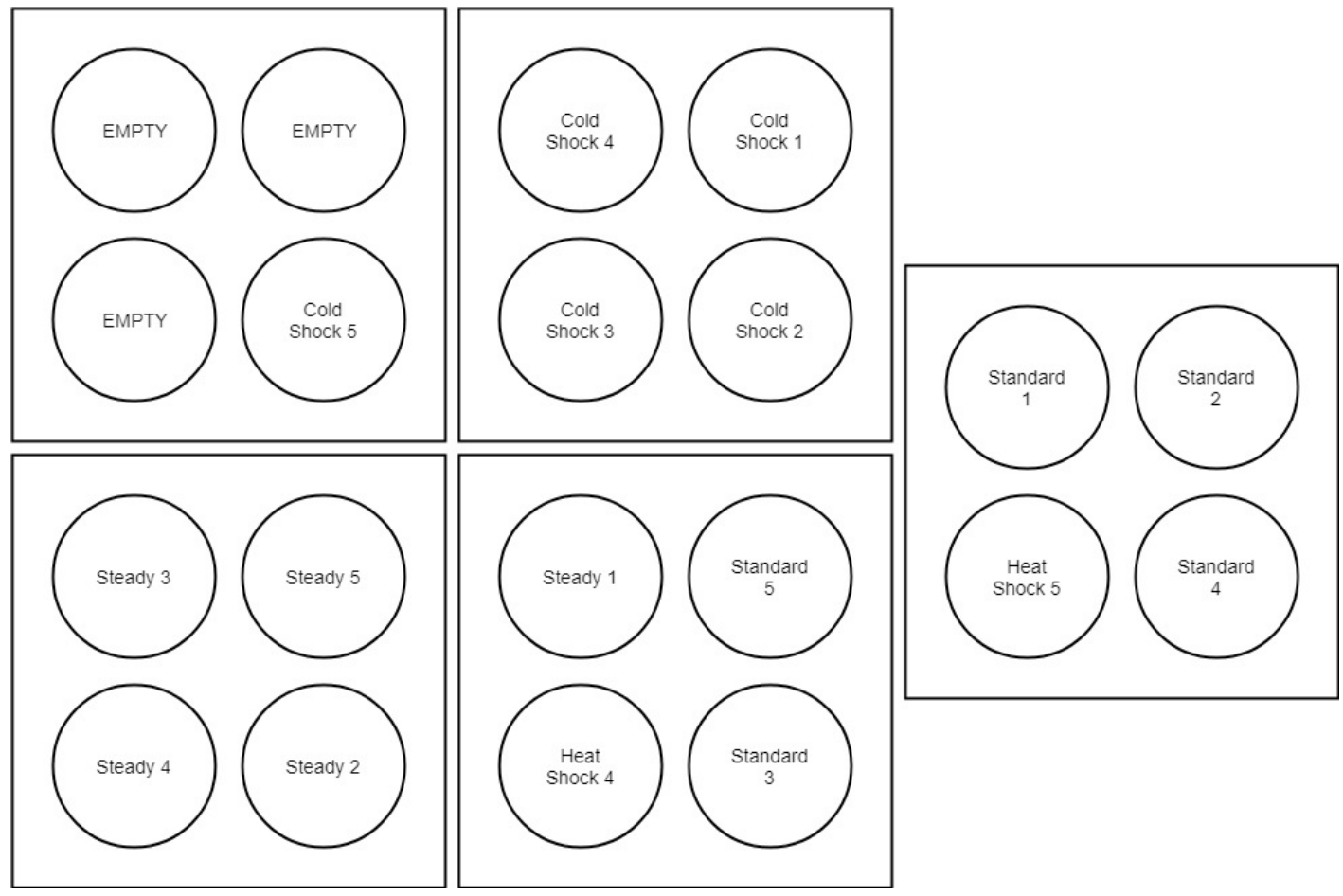

Figure 2 Larval Development Experimental Design. Once larvae hatched out, they were moved into larger buckets for grow out observations. Larval buckets were set up as hatch-out occurred. Maximum number of larvae were moved from each replicate. "Empty" buckets indicate three buckets that were unused due to the heat shock treatment causing three replicates to completely fail to produce larvae.All the replicates were on the same temperature system.

\section{Data collection}

Initial egg parameters were collected the day of spawning (Oct. $9^{\text {th }}$, 2018). Five one-milliliter samples of each egg ribbon were collected to estimate total egg count, egg volume $\left(\mathrm{mm}^{3}\right)$, oil drop volume $\left(\mathrm{mm}^{3}\right)$, and fertilization rates $(\%)$ prior to separation into replicates. At the end of incubation, three egg ribbon samples per segment were collected to quantify egg mortalities: dead eggs: completely opaque egg (\%), failed larvae: eyed up larvae but opaque (\%), and viable larvae: eyed up larvae and translucent or a ruptured empty egg (\%) (Figure 3). Larval parameters were collected once hatch out occurred. Initial lengths of larvae were taken day of hatch out. Larvae were moved into grow out buckets held at the same temperature for the duration of the larval phase( 28 days $),{ }^{35}$ and mortalities were recorded. Larval lengths were measured from recovered mortalities every four days for growth rates. All mortalities for each replicate were preserved in formalin in case any samples needed to be re-evaluated. At the end of the larval period all surviving larvae from each replicate were measured for final length. Estimated mortality (\%) was calculated to account for any discrepancies between initial number, Observed Mortalities (recovered dead larvae) (\%), and Survivals (\%).

$$
\text { Observed Mortalities }=\frac{\text { Recovered } \text { Mortalities }}{\text { Total Mortalities }} \times 100
$$

$$
\text { Est.Mortalities }=\frac{\text { Intial Count of Larvae }- \text { Final Count of Larvae }- \text { Observed Mortalities }}{\text { Total Mortalities }} \times 100
$$

$$
\text { Survival }=\frac{\text { Final Count of Larvae }}{\text { Intial Count of Larvae }} \times 100
$$

All egg and larval measurements were taken using Image (version $1.52 \mathrm{k}$, January 2019) image analysis software (National Institute of Health, Bethesda, MD, http://imagej.nih.gov/ij). Digital images were taken using Canon EOS RebelT5i camera.

\section{Statistical analyses}

Statistical analyses were carried out with JMP Pro 14(SAS Institute, Cary, $\mathrm{NC})$. Skein weight (g), egg count, egg volume $\left(\mathrm{mm}^{3}\right)$, oil drop volume $\left(\mathrm{mm}^{3}\right)$, and the oil drop volume to total egg volume ratio were assessed to determine relationships between one another using a linear regression. Egg and oil drop volumes were calculated using diameters assuming a spherical shape:

$$
\text { Volume }=\frac{1}{6} \pi d^{3}
$$

The ratio of oil drop volume to total egg volume was calculated using:

$$
\frac{\text { oil drop volume }\left(\mathrm{mm}^{3}\right)}{\text { total egg volume }\left(\mathrm{mm}^{3}\right)}
$$



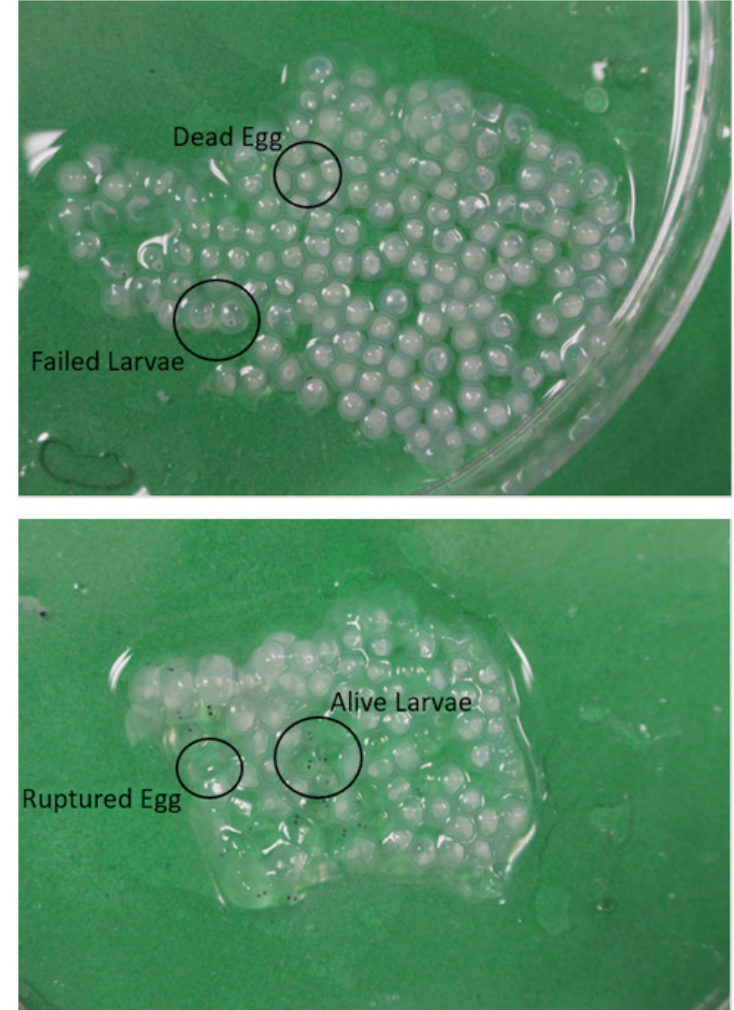

Figure 3 Photographic Examples of Embryonic Development at the end of incubation. Images were taken using Canon EOS RebelT5i camera. Top image shows what counted as a dead egg and as failed larvae. The bottom image shows what counted as viable larvae.

To determine if there was a difference between ribbon parameters described above between temperature treatments unpaired $t$-tests were conducted. Randomized block $F$-test with a Tukey-Kramer HSD post-hoc test was used to analyze embryonic development dependent variables: percent viable larvae, failed larvae, and dead eggs. Randomized block $F$-test with Tukey-Kramer HSD post-hoc tests were used with larval dependent variables: time to hatch, percent survival (\%), observed and estimated mortality (\%), initial size ( $\mathrm{mm})$, average growth rate ( $\mathrm{mm} /$ day), and final size $(\mathrm{mm})$ (See Appendix B). The formula used to calculate average growth rates:

$\frac{\sum\left(\frac{\Delta \text { Length }(m m)_{\text {Day } 1-5}}{\# \text { of days }}\right),\left(\frac{\Delta \text { Length }(\mathrm{mm})_{\text {Day } 6-9}}{\# \text { of days }}\right), \ldots,\left(\frac{\Delta \text { Length }(\mathrm{mm})_{\text {Day } 26-28}}{\text { \#of days }}\right)}{\text { total } \# \text { of days }(28)}$

For all statistical analyses, means were considered significantly different when $p<0.05$.

\section{Results}

\section{Temperature and embryonic development}

Egg ribbon sections weighed between 72.5 to $90.9 \mathrm{~g}$ among the replicates. Mean weights $( \pm \mathrm{SD})$ for the standard, steady, heat shock, and cold shock temperature treatments were as follows: $80.8 \mathrm{~g}$ $( \pm 4.7) ; 82.7 \mathrm{~g}( \pm 7.6) ; 79.5 \mathrm{~g}( \pm 5.2) ; 85.1 \mathrm{~g}( \pm 5.2)$ (Table 1a). There was no significant difference between temperature treatments for both weights of egg ribbon sections and egg amounts. A positive relationship emerged between weight of skein section $(\mathrm{x})$ and the number of eggs $(\mathrm{y})\left(\mathrm{y}=280.2 \mathrm{x}+607.6, \mathrm{r}^{2}=0.23, \mathrm{df}=19, p=0.033\right)$. Total number of eggs ranged from 18,500 to 30,960 per replicate. All other egg parameters (e.g. egg volume, oil drop volume, and oil drop to total egg volume ratio) showed no significant difference between temperature treatments (Table $1 \mathrm{~b}$ ). There was a negative relationship between average egg volumes (x) and the ratio of oil drop to total egg volume (y) ( $\left.\mathrm{y}=0.04-0.01 \mathrm{x}, \mathrm{r}^{2}=0.79, \mathrm{df}=19, P<0.0001\right)$.

Temperature treatment did not have a significant impact on the percent of dead eggs at the end of the incubation period ( $P=0.0958$, $\left.\mathrm{F}_{3,12}=2.66\right)$. Temperature treatment had a significant impact on the percent of failed larvae at the end of the incubation period ( $P=0.0005$, $\mathrm{F}_{3,12}=12.5$, Figure $\left.4 \mathrm{a}\right)$. Tukey tests showed the cold shock treatment average percent of failed larvae $(0.8 \%)$ was significantly lower than the steady treatment average $(22.9 \%)(P=0.0011)$ and the heat shock average $(17.6 \%)(P=0.0092)$. The standard treatment average $(3.8 \%)$ was also significantly lower than the steady treatment average $(P=0.0036)$ and the heat shock treatment average $(P=0.0312)$.The cold shock treatment had the lowest percent of failed larvae $(0.8 \%)$ while the steady treatment had the highest percent $(22.9 \%)$ (Table 2). Temperature treatment had a significant impact on the percent of viable larvae $\left(P=0.0425, \mathrm{~F}_{3,12}=3.71\right.$, Figure $\left.4 \mathrm{~b}\right)$. The cold shock treatment average $(49.6 \%)$ was significantly higher than the heat shock treatment average $(19.9 \%)(P=0.0325)$ (Table 2$)$.

Table la Egg ribbon metrics by treatment. Mean egg ribbon weights $( \pm S D)$ per temperature treatment. Egg counts and fertilization rates $( \pm S D)$ per temperature treatment were calculated using ImageJ

\begin{tabular}{llll}
\hline Treatment & Ribbon weight $(\mathbf{g})$ & Egg count & Fertilization rate (\%) \\
\hline Steady & $82.7( \pm 7.6)$ & $23,500( \pm 301)$ & $99.95( \pm 0.02)$ \\
Standard & $80.8( \pm 4.7)$ & $23,300( \pm 284)$ & $99.95( \pm 0.55)$ \\
Cold Shock & $85.1( \pm 5.2)$ & $23,700( \pm 177)$ & $99.95( \pm 1.01)$ \\
Heat Shock & $79.5( \pm 5.2)$ & $23,800( \pm 296)$ & $99.95( \pm 0.89)$
\end{tabular}

Table Ib Egg ribbon metrics by female yellow perch used in study. Averages per temperature treatment from ribbon sections of the same female in each treatment. Egg and oil drop volumes $( \pm S D)$ were calculated based on diameter measurements using Imagej. Oil drop to total egg volume ratio was calculated per female

\begin{tabular}{llll}
\hline Female length $(\mathbf{m m})$ & Avg. egg volume $\left(\mathrm{mm}^{3}\right)$ & Avg. Oil drop volume $\left(\mathrm{mm}^{3}\right)$ & Oil drop to total egg volume ratio \\
\hline 293 & $2.40( \pm 0.03)$ & $0.05( \pm 0.003)$ & 0.02 \\
302 & $3.10( \pm 0.01)$ & $0.04( \pm 0.001)$ & 0.01 \\
326 & $2.10( \pm 0.02)$ & $0.05( \pm 0.001)$ & 0.02 \\
320 & $2.70( \pm 0.04)$ & $0.06( \pm 0.005)$ & 0.02 \\
309 & $3.20( \pm 0.06)$ & $0.04( \pm 0.003)$ & 0.01 \\
\hline
\end{tabular}

Citation: Schmitz AM, Sepulveda Villet OJ. Short term temperature fluctuations affect embryonic and larval development of yellow perch (Perca flavescens).J Aquac Mar Biol. 202 I; 10(4):I68-I76. DOI: 10.15406/jamb.2021.10.003 I8 
Table 2 Embryonic development of each treatment at the end of the incubation period.Viable larvae include alive formed larvae and ruptured eggs indicating successful hatch. Dead eggs are completely opaque eggs. Failed larvae are completely opaque formed larvae that died before hatch-out. Counts of each category were performed with Image]. Tukey-Kramer HSD post hoc results are in parentheses next to treatments means. Treatment means that share the same letter are not significantly different from one another

\begin{tabular}{llll}
\hline Treatment & Percent viable larvae (\%) & Percent dead eggs (\%) & Percent failed larvae (\%) \\
\hline Steady & $27.9(\mathrm{ab})$ & 49.2 & $22.9(\mathrm{a})$ \\
Standard & $30.8(\mathrm{ab})$ & 65.4 & $3.8(\mathrm{~b})$ \\
Cold Shock & $49.6(\mathrm{a})$ & 49.6 & $0.8(\mathrm{~b})$ \\
Heat Shock & $19.9(\mathrm{~b})$ & 62.5 & $17.6(\mathrm{a})$ \\
\hline
\end{tabular}
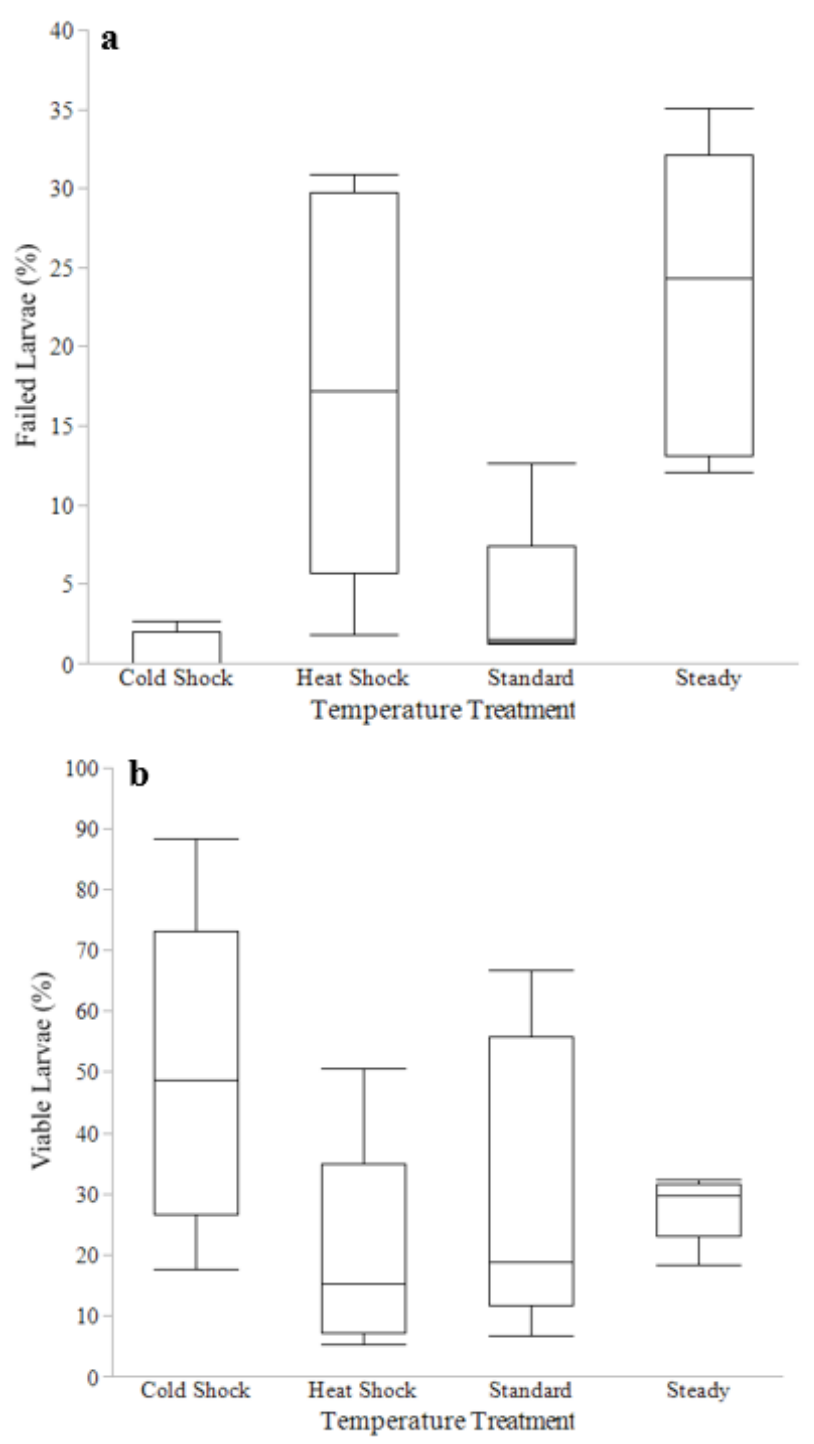

Figure 4 a) Percent (\%) failed larvae at the end of incubation per temperature treatment. Interquartile range, maximum percent and minimum percent are shown for each treatment. Randomized Block F-test revealed temperature treatments did have an effect on the percent of failed larvae $(P=0.0005$, $\left.F_{3,12}=12.5\right)$ b) Percent (\%) of viable larvae at the end of incubation per temperature treatment. Interquartile range, maximum percent and minimum percent are shown for each treatment. Randomized Block F-test revealed temperature treatments did have an effect on the percent of viable larvae $\left(P=0.0425, F_{3,12}=3.71\right)$.

\section{Temperature and larval development}

The heat shock temperature treatment and final size variable were not included in the larval analyses due to poor survival. Temperature treatment did have a significant impact on the time it took for larvae to successfully hatch out $\left(P<0.001, \mathrm{~F}_{2,8}=76\right.$, Table 3 , Figure $5)$. The steady treatment larvae started hatching after 10 days postfertilization (dpf) and finished hatching after 11 days which was significantly faster than both the standard treatment $(P<0.001)$ and the cold shock treatment $(P<0.001)$. The standard treatment larvae started hatching out $12 \mathrm{dpf}$ and finished hatching out after 13 days. The cold shock treatment larvae took the longest, hatching out after $13 \mathrm{dpf}$ which was significantly longer than the standard treatment $(P<0.0148)$. Temperature treatment did not have an impact on the initial size of larvae $\left(P=0.116, \mathrm{~F}_{28}=2.85\right)$. Temperature treatment did not have an impact on observed mortality and estimated mortality $\left(P=0.96, \mathrm{~F}_{2,8}=0.03\right)$. Temperature treatment did not impact the percent of surviving larvae $\left(P=0.35, \mathrm{~F}_{2,8}=1.19\right)$. Temperature treatment did not impact the average growth rate of larvae $\left(P=0.16, \mathrm{~F}_{2,8}=2.31\right)$.

\section{Discussion}

\section{Role of temperature on embryonic development}

Our study found that temperature did not cause an increase or decrease of egg mortality between treatments. We believe this is due to the importance that fertilization plays in initial development. However, it has been documented that variable thermal shocks have increased the mortality of incubating eggs of warm-water fish species. ${ }^{18}$ Yellow perch egg ribbons can result in erratic mortality patterns both in the wild and culture setting. However, variation in egg mortality could be minimized in yellow perch given how dependent the species is on water temperature. ${ }^{5,22}$ Further investigation into the factors impacting egg mortality may provide higher insight for wild populations.

Water temperature had the most impact on the percent of failed larvae. The cold shock treatment had the lowest percent of failed larvae while both the heat shock and the steady treatment had the highest percent failed. The cold shock treatment appeared to negate the failed larvae phenomenon that occurs in yellow perch embryonic development. Our findings contradict previous studies that claim acute cold fronts decrease the survival of yellow perch embryos and subsequently lower the numbers of larvae are produced. ${ }^{36,37}$ The standard treatment also demonstrated low percent of failed larvae. Hokanson and Kleiner ${ }^{38}$ reported that yellow perch hatching percentage is the highest when water temperature rises by $0.5-1^{\circ} \mathrm{C}$ per day from an initial optimal temperature $\left(5-10^{\circ} \mathrm{C}\right)$. This supports the wide acceptance that a slow steady increase in temperature during incubations periods is optimal. 
Table 3 Average larval development metrics for temperature treatments. Average incubation period was calculated using the start of hatch-out through the end. Initial lengths $( \pm S D)$ and growth rate samples were measured using Imagej. Percent (\%) survival and mortalities were calculated from initial and final counts. Growth rate $( \pm S D)$ was calculated from samples taken every 4 days for 28 days. Tukey-Kramer HSD post hoc results are in parentheses next to treatments means. Treatment means that share the same letter are not significantly different from one another

\begin{tabular}{|c|c|c|c|c|c|c|c|c|}
\hline Treatment & $\begin{array}{l}\text { Incubation } \\
\text { Period }\end{array}$ & $\begin{array}{l}\text { Initial } \\
\text { Count }\end{array}$ & $\begin{array}{l}\text { Final } \\
\text { Count }\end{array}$ & $\begin{array}{l}\text { Initial } \\
\text { Length } \\
(\mathrm{mm})\end{array}$ & $\begin{array}{l}\text { Growth Rate } \\
\text { (mm/day) }\end{array}$ & $\begin{array}{l}\% \\
\text { Survival }\end{array}$ & $\begin{array}{l}\text { \% Mortality } \\
\text { (Observed) }\end{array}$ & $\begin{array}{l}\% \text { Mortality } \\
\text { (Estimated) }\end{array}$ \\
\hline Steady & $10.5(c)$ & $332(66)$ & $6(1.2)$ & $5.30( \pm 0.30)$ & 0.10 & 2.30 & 52.7 & 47.9 \\
\hline Standard & $12.0(b)$ & $330(66)$ & I (0.2) & $4.98( \pm 0.36)$ & 0.11 & 0.27 & 55.0 & 45.0 \\
\hline Cold Shock & I3.0 (a) & $375(75)$ & $4(0.8)$ & $4.96( \pm 0.27)$ & 0.12 & 1.07 & 53.6 & 46.4 \\
\hline
\end{tabular}
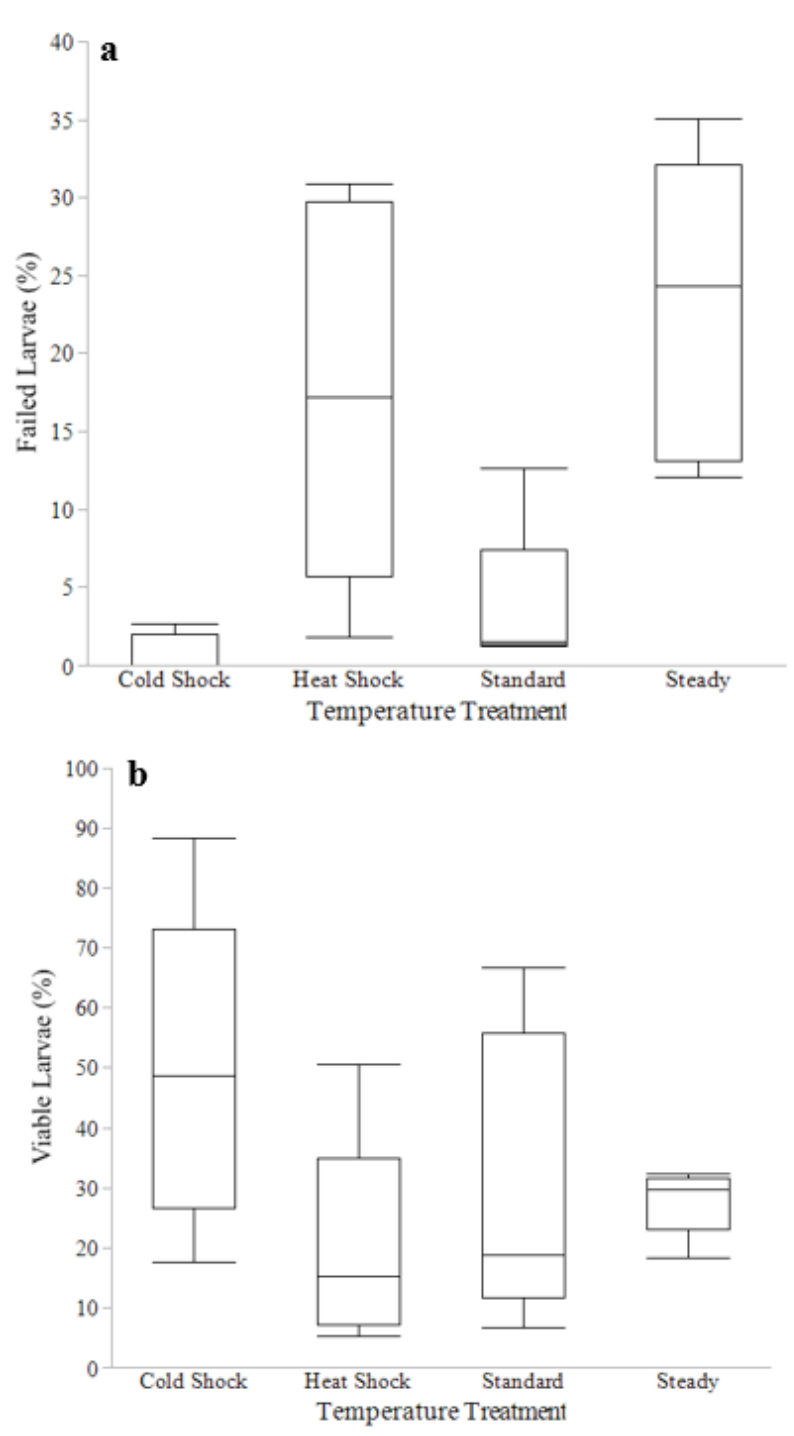

Figure 5 Total duration of incubation periods for each temperature treatment. Line I indicates the start of the hatching period for each treatment. Line 2 indicates the end of the hatching period if it extended multiple days. Randomized Block F-test revealed that temperature did have a significant effect on incubation period $\left(P<0.00 \mathrm{I}, \mathrm{F}_{2,8}=76\right)$. Heat shock treatment was included for comparison purposes but was not included in the statistical analysis.

We found temperature had a significant overall impact on the number of viable larvae produced. Jansen et al. ${ }^{27}$ also found that a decrease in water temperature simulating a spring cold-front had very little effect on the hatching success of yellow perch eggs. Landsman et al. ${ }^{11}$ found that both smallmouth bass (Micropterus dolomieu) and largemouth bass eggs were more resilient to acute cold changes in temperature than acute warm water changes. However, in colder than optimal temperatures the abundance of viable larvae decreases thus impacting overall survival of walleye larvae. ${ }^{10}$ In 2005 and 2009 ,average water temperatures during yellow perch spawning were low $\left(2005: 11^{\circ} \mathrm{C} ; 2009: 12.4^{\circ} \mathrm{C}\right)$ at Little Tail Point, Green Bay, a known spawning location for yellow perch. The following survey at that location for age-0 perch showed high abundances (2005: 7,310; 2009: 9,815). The heat shock treatment had the lowest percent of viable larvae in addition to causing three skein sections to completely fail by producing no viable larvae. Three days post-temperature exposure, the heat shock treatment embryonic development either sped up or completely failed. Data from Little Tail Point, Green Bay showed that 2007 and 2012 were unusually hot years $\left(2007: 16^{\circ} \mathrm{C} ; 2012: 16.9^{\circ} \mathrm{C}\right)$ during yellow perch spawning and larval periods. Those years, age- 0 yellow perch were at very low abundance (2007: 702; 2012: 985). Given the results of our study and others, it is evident that yellow perch may have adapted to withstand substantial cold shocks during embryonic development. ${ }^{23,27}$ Our findings concur with statements by Farmer et al. ${ }^{21}$ that yellow perch embryonic survival could be susceptible to short, warm winters that are predicted to increase in frequency.

\section{Role of temperature on larval development}

We found that temperature did determine the incubation period of yellow perch egg ribbons. The steady treatment hatched out only after 10 days of incubation. While the heat shock was not included due to lack of replication power, the two ribbons segments that produced larvae hatched out after between 10 to 11 days of incubation. The cold shock treatment was the only treatment that all ribbon segments hatched out on the same day (after 13 days of incubation). The cold shock treatment larvae development was normal although slower than the other treatments while the steady and heat shock larvae developed faster than normal for yellow perch. Bondarenko et al. ${ }^{19}$ found that when incubation temperatures fell outside the normal range for northern pike it resulted in a shift of the hatching period by either prolonging or accelerating embryonic development. Previous studies also have documented that low temperatures during incubation slows development and growth of eggs as well as larvae. ${ }^{9},{ }^{18}$ Lyons et al ${ }^{17}$ found that yellow perch in Lake Michigan were shifting spawning time in order to align with preferred spawning temperature. However, yellow perch may not be adjusting spawning time fast enough to keep pace with projected warming water temperatures. ${ }^{21}$ Walleye have been documented shifting its reproductive phenology by two months earlier to match with preferred water temperatures in Lake Erie. ${ }^{16}$ Warm water species like centrarchids have also been documented having earlier spawning and hatch-out when water temperatures were warmer than average. ${ }^{18}$ 
We believe the low survival documented through the larval period impact edour ability to determine if temperature had an impact on larval development. The heat shock treatment produced low numbers of larvae and was not included in any statistical analyses for larval development. In addition to having to remove final size variable since some buckets had no survival by the end of the larval period. We believe that the low survival of larvae in our study was due to a high amount of cannibalism rather than the temperature treatments. Cannibalism is well documented in many fish species especially in early life stages. ${ }^{20,39}$ Cannibalism is highly prominent in predatory species used in aquaculture. ${ }^{39}$ Pagel et al. ${ }^{20}$ found that the earlier onset of cannibalism in northern pike resulted in a growth advantage since fast, early growth is positively related to survival. Schaefer et al. ${ }^{40}$ found that a wide variation in growth and size of larvae promotes cannibalism within cohorts. Cannibalism is a major problem in commercial production of predatory fish and ranges from $15 \%$ to $90 \%$ of individuals. ${ }^{39}$ Previous studies suggest that short and warm winters could weaken annual recruitment of yellow perch by decreasing initial larval survival. However, warm spring and summer temperatures have been linked to positive yellow perch and walleye recruitment across the Great Lakes. ${ }^{16}$ The predictions of more dynamic weather patterns during spring may only increase the occurrence of erratic recruitment patterns in yellow perch populations. ${ }^{5}$ In order to determine if climate change will impact initial larval survival more studies will need occur with higher replication in order to account for potential cannibalism related mortalities.

While survival through the larval phase was low due to cannibalism, we did start to see some trends in initial size and growth of larvae. The steady treatment hatched out the earliest and was initially the largest $(5.36 \mathrm{~mm})$. However, it had a slower growth rate $(0.07 \mathrm{~mm} /$ day $)$ compared to the cold shock treatment $(0.105 \mathrm{~mm} /$ day $)$ and the standard treatment $(0.108 \mathrm{~mm} /$ day $)$.Previous studies support the claim of yellow perch larvae that hatch out later exhibit faster growth rates than larvae with earlier hatch dates. ${ }^{5,28}$ Kaemingk et al. ${ }^{2}$ also found water temperature and hatch date had a positive impact on larval yellow perch growth rates. Studies have also found that in centrarchids, early hatching has increased growth advantages. ${ }^{20}$ Growth rates commonly determine survival of larval yellow perch in northern regions due to the shorter growing seasons. ${ }^{5}$ Dembkowski et $\mathrm{al}^{26}$ found that environmental conditions experienced during the post-emergence period could play a larger role in larval yellow perch abundance than those during spawning and incubation periods. A reduction of reproductive success has been found in wild yellow perch following short warm winters by a decline in hatching success and smaller larval sizes at hatch-out. ${ }^{5,21}$ Pagel et al. ${ }^{20}$ found that northern pike that hatched out early in the season under cooler water temperatures did not grow as well as late-season larvae that hatched when water temperatures were warming to more favorable growth conditions. Similar results have been documented in walleye larvae where total length of larvae increased as temperatures warmed. ${ }^{10}$ Further replication is needed in order to confirm the trend of water temperature impacting initial length and growth rates in larval yellow perch. $^{41-54}$

\section{Conclusions}

These results provide evidence that yellow perch embryonic development is highly dependent on water temperature during the incubation period. The cold shock treatment has a low percent of failed larvae and a high percent of viable larvae. The standard treatment which is commonly accepted as the optimal incubation condition, had a low percent of failed larvae in addition to having a high percent of viable larvae. The heat shocks results show that yellow perch are not well adapted to acute warm temperature changes. This treatment clearly damaged developing embryos in addition to causing massive mortality events. This suggests that wild yellow perch will not be able to adapt spawning phenology enough to keep up with increasing water temperatures predicted to occur with climate change.

This study also confirms that temperature impacts the incubation period. We found that warmer temperature treatments (steady and heat shock) shortened the incubation period while the cold shock and standard treatments were significantly longer. The cold shock treatment all hatched on the same day potentially decreasing growth variation and increasing food competition. The steady treatment larvae hatched out the earliest and were larger with slower growth rates compared to the cold shock and standard treatments. However, more research with higher replication will be needed in order to conclude if water temperature has an impact on larval development.

\section{Acknowledgments \& funding}

The authors thank Frederick P. Binkowski, in securing fertilized yellow perch eggs from the UWM yellow perch genetic improvement program. Thank you to B. Shepherd, USDAARS, for lending valuable equipment for this project. Essential guidance and feedback was provided by J. Janssen and T. Paoli (UWM and WIDNR, respectively). This work was supported by Wisconsin Sea Grant [Grant number 144 AAB3869], the North Central Regional Aquaculture Center [grant number 2014-28500-25753], and the University of WisconsinMilwaukee Research Growth Initiative Project "Epigenetic Transgenerational Impacts of Great Lakes Chemicals of Concern". The authors have no conflict of interests to declare.

\section{Conflicts of interest}

The authors have no conflict of interest.

\section{References}

1. Young JL, ZB Bornik, ML Marcotte. Integrating Physiology and Life History to Improve Fisheries Management and Conservation. Fish and Fisheries. 2006;7(4):262-283.

2. Kaemingk MA, BDS Graeb, DW Willis. Temperature, Hatch Date, and Prey Availability Influence Age-0 Yellow Perch Growth and Survival. Transactions of the American Fisheries Society. 2014;143(4):845-855.

3. Prokešová M, B Drozd, J Kouřil. Effect of Water Temperature on Early Life History of African Sharp-Tooth Catfish, Clarias gariepinus (Burchell, 1822). Journal of Applied Ichthyology. 2015;31:18-29.

4. Arula T, T Raid, M Simm, et al. Temperature-Driven Changes in Early Life-History Stages Influence the Gulf of Riga Spring Spawning Herring (Clupea harengus m.) Recruitment Abundance. Hydrobiologia. 2016;767:125-135

5. Bogner DM, MA Kaemingk, MR Wuellner. 2016. Consequences of Hatch Phenology on Stages of Fish Recruitment. PLOS ONE. 2016.11,10: e0164980.

6. Garrido S, R Ben-Hamadou, AMP Santos, 2015. Born Small, Die Young: Intrinsic, Size-Selective Mortality in Marine Larval Fish. Scientific Reports. 2015;5:17065.

7. Forsythe PS, KT Scribner JA Crossman, et al. Experimental Assessment of the Magnitude and Sources of Lake Sturgeon Egg Mortality. Transactions of the American Fisheries Society. 2013;142(4):1005-1011.

8. Vindenes Y, Ø Langangen IJ, Winfield. Fitness Consequences of Early Life Conditions and Maternal Size Effects in a Freshwater Top Predator. $J$ Anim Ecol. 2016;85(3):692-704. 
9. Morgan RP, VJ Rasin. Influence of Temperature and Salinity on Development of White Perch Eggs. Transactions of the American Fisheries Society. 1982(3);111:396-398.

10. Rutherford ES, J Allison, CR Ruetz III, et al. Density and Survival of Walleye Eggs and Larvae in a Great Lakes Tributary. Transactions of the American Fisheries Society. 145, no. 3 (2016):563-577.

11. Landsman SJ, AJ Gingerich DP. Philipp, The Effects of Temperature Change on the Hatching Success and Larval Survival of Largemouth Bass Micropterus salmoides and Smallmouth Bass Micropterus dolomieu. Journal of Fish Biology. 2011;78(4):1200-1212.

12. Lee AH, J Eme, CA Mueller, et al. The Effects of Increased Constan Incubation Temperature and Cumulative Acute Heat Shock Exposures on Morphology and Survival of Lake Whitefish (Coregonus clupeaformis) Embryos. Journal of Thermal Biology. 2016;57:11-20.

13. Ohlberger J, Ø Langangen. Population Resilience to Catastrophic Mortality Events during Early Life Stages. Ecological Applications. 2015;25:1348-1356.

14. Patrick PH, E Chen, J Parks, et al . Effects of Fixed and Fluctuating Temperature on Hatch of Round Whitefish and Lake Whitefish Eggs. North American Journal of Fisheries Management. 2013;33(6):10911099

15. Feiner ZS, HY Wang, DW Einhouse, et al. Thermal Environment and Maternal Effects Shape Egg Size in a Freshwater Fish. Ecosphere. 2016;7(5):e01304.

16. Collingsworth PD, DB Bunnell, MW Murray, et al. Climate Change as a Long-Term Stressor for the Fisheries of the Laurentian Great Lakes of North America. Reviews in Fish Biology and Fisheries. 2017;27: 363391.

17. Lyons J, AL Rypel, PW Rasmussen, et al. Trends in the Reproductive Phenology of Two Great Lakes Fishes. Transactions of the American Fisheries Society. 2015;144:1263-1274.

18. Murphy SC, NC Collins, SE Doka. The Effects of Cool and Variable Temperatures on the Hatch Date, Growth and Overwinter Mortality of a Warm water Fish in Small Coastal Embayments of Lake Ontario. Journal of Great Lakes Research. 2012;38(3):404-412.

19. Bondarenko V, B Drozd, T Policar. Effect of Water Temperature on Egg Incubation Time and Quality of Newly Hatched Larvae of Northern Pike (Esox lucius L., 1758). Journal of Applied Ichthyology. 2015;31: 45-50.

20. Pagel T, D Bekkevold S, Pohlmeier C, et al. . Thermal and Maternal Environments Shape the Value of Early Hatching in a Natural Population of a Strongly Cannibalistic Freshwater Fish. Oecologia. 2015;178(4):951965.

21. Farmer TM, EA Marschall, K Dabrowski, et al. Short Winters Threaten Temperate Fish Populations. Nature Communications. 2015;6:7724.

22. Marsden JE, SR Robillard. Decline of Yellow Perch in Southwestern Lake Michigan, 1987-1997. North American Journal of Fisheries Management. 2004;24(3):952-966

23. VanDeHey JA, MA Kaemingk AC Jansen, Effects of Simulated Cold Fronts on the Survival and Behaviour of Yellow Perch Perca flavescens Yolk-Sac Fry. Journal of Applied Ichthyology. 2013;29:364-367.

24. Dembkowski DJ, DW Willis, MR Wuellner. Synchrony in Larval Yellow Perch Abundance: The Influence of the Moran Effect during Early Life History. Canadian Journal of Fisheries and Aquatic Sciences. 2016;73: 1567-1574.

25. Redman RA, SJ Czesny, JM Dettmers. Old Tales in Recent Context: Current Perspective on Yellow Perch Recruitment in Lake Michigan. Transactions of the American Fisheries Society. 2011;140(5):12771289.
26. Dembkowski DJ, MJ Weber, MR Wuellner. 2017. Factors Influencing Recruitment and Growth of Age-0 Yellow Perch in Eastern South Dakota Glacial Lakes. Fisheries Management and Ecology. 2017;24(5):372-381.

27. Jansen AC, BDS Graeb, DW Willis. Effect of a Simulated Cold-Front on Hatching Success of Yellow Perch Eggs. Journal of Freshwater Ecology. 2009;24(4):651-655.

28. Weber MJ, JM Dettmers, DH Wahl. Growth and Survival of Age-0 Yellow Perch across Habitats in Southwestern Lake Michigan: Early Life History in a Large Freshwater Environment. Transactions of the American Fisheries Society. 2011;140:1172-1185.

29. Janssen J, JE Marsden T Hrabik, et al. Are the Laurentian Great Lakes Great Enough for Hjort?. ICES Journal of Marine Science. 2014;71: $2242-2251$

30. Roloson SD, RL Gould, DR Barton, et al. Factors Influencing Growth Variability in Three Northern Alberta Populations of Yellow Perch (Perca flavescens). Journal of FisheriesSciences.com. 2016;10:43-52.

31. Zhang F, KB Reid, TD Nudds. Relative Effects of Biotic and Abiotic Factors during Early Life History on Recruitment Dynamics: A Case Study. Canadian Journal of Fisheries and Aquatic Sciences. 2017;74(7):1125-1134.

32. Dembkowski DJ, MJ Weber, MR Wuellner. Factors Influencing Recruitment and Growth of Age-0 Yellow Perch in Eastern South Dakota Glacial Lakes. Fisheries Management and Ecology. 2017;24(5):372-381.

33. Glogowski J, A Ciereszko, K Dabrowski. Cryopreservation of Muskellunge and Yellow Perch Semen. North American Journal of Aquaculture. 1999;61(3):258-262.

34. Miller ME, M Kemski JD, Grayson K, et al. Yellow Perch Sperm Motility, Cryopreservation, and Viability of Resulting Larvae and Juveniles. North American Journal of Aquaculture. 2018;80(1):3-12.

35. Mansueti A J. Early Development of the Yellow Perch, Perca Flavescens. Chesapeake Science. 1964;5:46.

36. Longhenry CM. Yellow Perch Production in Semi-Permanent Wetlands in Eastern South Dakota and Evaluation of a New Chemical Marking Tool for Juvenile Yellow Perch. MS Thesis. South Dakota State University, Brookings. 2006.

37. Jolley JC. Recruitment of Bluegill and Yellow Perch in Nebraska Sandhills Lakes: Integrating Multiple Life Stages. 1-263. PhD Dissertation. South Dakota State University, Brookings. 2009.

38. Hokanson KEF, CF Kleiner. Effects of Constant and Rising Temperatures on Survival and Developmental Rates of Embryonic and Larval Yellow Perch, Perca flavescens (Mitchill). In: Blaxter JHS. editor. The Early Life History of Fish. Springer, Berlin, Heidelberg. 1974:437-448

39. Naumowicz K, J Pajdak E. Terech-Majewska, et al. Intracohort Cannibalism and Methods for Its Mitigation in Cultured Freshwater Fish. Reviews in Fish Biology and Fisheries. 2017;27:193-208.

40. Schaefer FJ, S Flues, S Meyer, et al. Inter- and Intra-Individual Variability in Growth and Food Consumption in Pikeperch, Sander lucioperca L., Larvae Revealed by Individual Rearing. Aquaculture Research. 2017;48(3):800-808.

41. Brown PB, K Dabrowski, DL Garling. Nutrition and Feeding of Yellow Perch (Perca flavescens). Journal of Applied Ichthyology. 1996;12:171174.

42. Brown PB, JE Wetzel J, Mays KA, et al. Growth Differences Among Stocks of Yellow Perch, Perca flavescens, Are Temperature Dependent. Journal of Applied Aquaculture. 2002;12(1):43-56.

43. Hart SD, DL Garling, JA Malison. Yellow Perch Culture Guide. NCRAC Culture Series. 2006;103:1-93. 
44. Jůza T, M Čech, J Kubečka, et al. The Influence of the Trawl Mouth Opening Size and Net Colour on Catch Efficiency during Sampling of Early Fish Stages. Fisheries Research. 2010;105(3):125-133.

45. Kolkovski SK. Dabrowski. Off-Season Spawning of Yellow Perch. The Progressive Fish-Culturist. 1998;60(2):133-136.

46. Malison JA. A White Paper on the Status and Needs of Yellow Perch Aquaculture in the North Central Region" Prepared for: North Central Regional Aquaculture Center. (2003):18 p.

47. Mangel M J, Brodziak G, DiNardo. Reproductive Ecology and Scientific Inference of Steepness: A Fundamental Metric of Population Dynamics and Strategic Fisheries Management. Fish and Fisheries. 2010;11(1):89104.

48. Mecozzi M. Fishes of Wisconsin: Yellow Perch. Wisconsin Department of Natural Resources Bureau of Fisheries Management. 2008;5.

49. Purchase CF, Collins NC, Morgan GE, et al. Predicting Life History Traits of Yellow Perch from Environmental Characteristics of Lakes. Transactions of the American Fisheries Society. 2005;134(5):1369-1381.
50. Rosauer DR, PR Biga, SR Lindell, et al. Development of Yellow Perch (Perca flavescens) Broodstocks: Initial Characterization of Growth and Quality Traits Following Grow-out of Different Stocks. Aquaculture. 2011;317(1-4):58-66.

51. Suchocki, C. R. and O.J. Sepulveda-Villet. The Role of Phototaxis in the Initial Swim Bladder Inflation of Larval Yellow Perch (Perca Flavescens). International Aquatic Research. 2019;11:33-42.

52. Taylor SG. Climate Warming Causes Phenological Shift in Pink Salmon, Oncorhynchus Gorbuscha, Behavior at Auke Creek, Alaska. Global Change Biology. 2007;14: 229-235.

53. United States Department of Interior (USDI). Great Lakes Fishery Resources Restoration Study Report. US. Fish and Wildlife Service, Washington DC. 1995;1-198.

54. Wiedenmann J, TE Essington. Density-Dependent Overwinter Survival in Young-of- Year Bluefish (Pomatomus saltatrix)? A New Approach for Assessing Stage Structured Survival. Canadian Journal of Fisheries and Aquatic Sciences. 2006;63:1934-1943. 